\title{
High-Temperature Reactions of Hexafluorobenzene
}

\author{
Joseph M. Antonucci and Leo A. Wall \\ Institute for Materials Research, National Bureau of Standards, Washington, D.C., 20234
}

(July 19, 1966)

\begin{abstract}
The direct replacement of aromatic fluorine in hexafluorobenzene has hitherto been possible only by the use of nucleophilic reagents. In this investigation, the replacement of nuclear fluorine by nonnucleophilic, or weakly nucleophilic, reagents was achieved by reaction at relatively high temperatures, 300 to $850^{\circ} \mathrm{C}$. For example, the reaction of hexafluorobenzene with such reagents as bromine, chlorine, and tetrafluoroethylene gave as major products bromopentafluorobenzene, chloropentafluorobenzene, and octafluorotoluene. In addition, pentafluorohalobenzenes can also be produced by passage of hexafluorobenzene over the appropriate alkali or alkaline earth-metal halides at elevated temperatures.

The mechanism of the pyrolytic reactions of hexafluorobenzene and the nonionic coreactants are considered to involve free-radical intermediates. The reaction of hexafluorobenzene with the ionic coreactants may proceed by an ionic mechanism similar to that advanced for the usual, relatively low-temperature, nucleophilic substitution reactions of aromatic systems. However, a more complicated free radical-ionic process cannot be ruled out for these reactions.
\end{abstract}

Key Words: Direct replacement, high temperature, mechanisms, nonionic or ionic coreactants, nuclear fluorine, pentafluorohalobenzenes.

\section{Introduction}

Aromatic hydrocarbons can undergo substitution or displacement reactions by attack of an electrophilic, nucleophilic, or free-radical species. The most common aromatic substitution reactions, however, involve the attack of an electrophilic reagent on the aromatic ring, e.g., nitration, sulfonation, halogenation, and the Friedel-Crafts reaction.

In contradistinction to this behavior, the principal mode of aromatic substitution in hexafluorobenzene is by attack of a nucleophilic reagent. In fact, with few exceptions $[1-6],{ }^{1}$ all of the reactions of hexafluorobenzene that have been reported in the literature may be classed as bimolecular, nucleophilic, substitution reactions $[3,7-15]$. The feature common to all these reactions is the displacement of one or more of the ring fluorines as the fluoride ion, by a nucleophile of sufficient strength. The general reaction is indicated by the following equation,

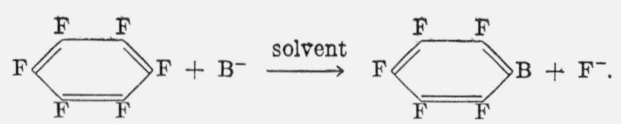

$\mathrm{B}^{-}$represents the nucleophilic reagent, which may be (1) an anionic base, such as potassium hydroxide, sodium hydrogen sulfide, sodium amide, sodium ethox-

\footnotetext{
${ }^{1}$ Figures in brackets indicate the literature references at the end of this paper.
}

ide, etc., (2) a carbanionic base, such as various Grignard reagents and organolithium reagents, or (3) an uncharged base such as ammonia, primary and secondary amines, hydrazine, etc. In general, these nucleophilic reactions are usually conducted in solvents and at moderate temperatures, usually well below $300{ }^{\circ} \mathrm{C}$.

Although hexafluorobenzene undergoes nucleophilic attack with comparative ease, the molecule appears to be quite inert to electrophilic attack [1,2]. Obviously, the highly unfavorable energetics involved in the expulsion of a nuclear fluorine atom as the fluorine cation, $\mathrm{F} \oplus$, would make such electrophilic reactions as halogenation, sulfonation, nitration, and the Friedel-Crafts reaction rather difficult, if not totally impossible.

Thus, the very nature of the electronic structure of hexafluorobenzene would appear to preclude, for this aromatic molecule, the usual electrophilic reactions that are associated with aromatic hydrocarbons.

Hexafluorobenzene, however, is susceptible to freeradical attack. The few nonnucleophilic reactions of this molecule that have been reported have indeed involved this type of attack. For example, hexafluorobenzene adds chlorine quite readily under rather mild conditions to give hexachlorohexafluorocyclohexane [1-3]. The catalytic reduction of hexafluorobenzene with hydrogen to penta- and tetra-fluorobenzene at 300 ${ }^{\circ} \mathrm{C}$, using a platinum catalyst, probably proceeds by a free-radical mechanism [4]. Although the addition of chlorine to hexafluorobenzene is an example of a free-radical addition reaction, the reduction of hexafluorobenzene with hydrogen is classified as a freeradical substitution reaction. 
One of the earliest and, perhaps, most complicated reactions of hexafluorobenzene is one reported by Desirant $[1,2]$. This interesting reaction, which is the only example of a high-temperature (above $300{ }^{\circ} \mathrm{C}$ ) reaction of hexafluorobenzene reported to date, involves the pyrolysis of the molecule in a platinum reactor at $850{ }^{\circ} \mathrm{C}$. Among the many products produced in this reaction, octafluorotoluene and decafluorobiphenyl were identified. This highly complex reaction probably could also be classified, in some respects, as a free-radical substitution reaction.

There is also some less direct evidence that hightemperature reactions of hexafluorobenzene do occur. In the synthesis of hexafluorobenzene by the pyrolysis of tribromofluoromethane $[1,2,9,16,17]$, bromopentafluorobenzene is a significant by-product. Lesser amounts of higher brominated fluorocarbons are formed as well, along with copious quantities of bromine. This rather complex reaction is illustrated below,

$$
\mathrm{CFBr}_{3} \stackrel{630-640{ }^{\circ} \mathrm{C}}{>}>\mathrm{C}_{6} \mathrm{~F}_{6}+\mathrm{Br}_{2}
$$

$$
+\mathrm{C}_{6} \mathrm{~F}_{5} \mathrm{Br}+\mathrm{C}_{6} \mathrm{~F}_{4} \mathrm{Br}_{2}+\text { etc. }
$$

Two similar mechanisms have been postulated for the formation of hexafluorobenzene $[9,16,17]$, but none for the formation of the important by-product, bromopentafluorobenzene.

Since the pyrolysis of tribromofluoromethane could conceivably lead to the formation of bromofluorocarbene $(>\mathrm{CBrF})$ and bromine, one possible mechanism for the formation of hexafluorobenzene is that involving the transient intermediate, $>\mathrm{CBrF}$ as shown below,

$$
\begin{aligned}
& \text { (1) } 2>\mathrm{CBrF} \longrightarrow \mathrm{CBrF}=\mathrm{CBrF} \\
& \text { (2) } 3 \mathrm{CBrF}=\mathrm{CBrF} \stackrel{\mathrm{C}}{\longrightarrow}>\mathrm{C}_{6} \mathrm{Br}_{6} \mathrm{~F}_{6} \\
& \text { (3) } \mathrm{C}_{6} \mathrm{Br}_{6} \mathrm{~F}_{6} \longrightarrow \mathrm{C}_{6} \mathrm{~F}_{6}+3 \mathrm{Br}_{2}
\end{aligned}
$$

A second possible mechanism that has been postulated would involve the formation of difluoroacetylene $(\mathrm{CF} \equiv \mathrm{CF})$ and its subsequent cyclic trimerization to hexafluorobenzene [7,9].

The latter mechanism, since it does not involve any precursors that contain bromine, cannot account for the direct formation of any of the brominated derivatives of hexafluorobenzene. The former mechanism, although it does involve bromine-containing precursors, can only explain the formation of such products as bromopentafluorobenzene if debromofluorination (loss of $\mathrm{BrF}$ ) can occur to some extent along with the energetically more favored process of debromination (loss of $\mathrm{Br}_{2}$ ). It is conceivable that this situation may exist in a particular stereoisomer of hexabromohexafluorocyclohexane $\left(\mathrm{C}_{6} \mathrm{Br}_{6} \mathrm{~F}_{6}\right)$ that has a conformation that permits the loss of $\mathrm{BrF}$ to occur. Since the yield of bromopentafluorobenzene is small compared to that of hexafluorobenzene, it would seem that, if the transient intermediate $\left(\mathrm{C}_{6} \mathrm{Br}_{6} \mathrm{~F}_{6}\right)$ does exist, it exists primarily in stereoisomeric forms that favor the elimination of $\mathrm{Br}_{2}$ rather than that of $\mathrm{BrF}$, although the latter elimination could also occur if isomerization to a more favorable conformation developed during the debromination process. Two other possible transient intermediates that could also account for the formation of bromopentafluorobenzene are $\mathrm{C}_{6} \mathrm{Br}_{2} \mathrm{~F}_{6}$ and $\mathrm{C}_{6} \mathrm{Br}_{4} \mathrm{~F}_{6}$. The foregoing argument assumes, of course, that dehalogenation can only occur by means of a cis-elimination mechanism.

Also, it is conceivable that bromopentafluorobenzene and similar by-products might arise from secondary reactions of bromine with the newly formed hexafluorobenzene by a mechanism such as that shown,

$$
\mathrm{C}_{6} \mathrm{~F}_{6}+\mathrm{Br}_{2} \rightarrow \mathrm{C}_{6} \mathrm{~F}_{5} \mathrm{Br}+\mathrm{BrF} \text {, etc. }
$$

In the light of the early work of Desirant [1,2], which indicated that hexafluorobenzene does undergo hightemperature reactions without benefit of a coreagent, it would appear feasible that a reaction between hexafluorobenzene and such a coreagent as bromine could take place at the elevated temperatures employed in the pyrolysis of tribromofluoromethane.

\section{High-Temperature Reactions of Hexafluorobenzene}

\subsection{Reaction With Halogens}

\section{a. Bromine}

In order to test the possibility that hexafluorobenzene can undergo a free-radical substitution reaction with bromine at elevated temperatures, both these reagents were simultaneously passed through a heated reactor tube under various conditions. The reactor tube was usually made of high-silicate glass and packed with borosilicate glass helices. Other reactor tubes employed were platinum, steel, and quartz. In addition to borosilicate glass helices, other packing material included glass wool, carbon pellets, platinum gauze, and nickel turnings. A few experiments involving unpacked reactors were also tried. The results in all these cases were similar.

The examination of the pyrolyzates from several runs revealed the presence of significant amounts of bromopentafluorobenzene. In some cases, smaller amounts of polybromo derivatives of hexafluorobenzene were also noted. The conversion of hexafluorobenzene into products ranged from a few percent to about 25 percent. The yield of bromopentafluorobenzene, based on unrecovered hexafluorobenzene, was 85 to 95 percent. The yield of bromopentafluorobenzene, as expected, is dependent on such variables as (1) the temperature of the reactor, (2) the molar ratio of the reactants, (3) the contact time in the heated zone, and (4) the packing material and reactor material. The nature of the products is also dependent on the conditions of the reaction. For example, hexafluorobenzene and bromine, in the molar ratio of 1 to 3 , when passed through a reactor packed with 
borosilicate glass helices, gave at $650{ }^{\circ} \mathrm{C}$ an 8 percent conversion into bromopentafluorobenzene (95\% yield). However, at $740^{\circ} \mathrm{C}$ and with the other variables approxmately the same, the conversion into products was increased to 25 percent. Although bromopentafluorobenzene was still the major product ( $85 \%$ yield), other more highly brominated products began to appear. The yield of these products was about 10 percent, and the main constituent appeared to be, from an examination of its retention time on the vapor-phase chromatogram, one of the isomers of dibromotetrafluorobenzene.

\section{b. Chlorine}

The successful replacement of one or more nuclear fluorines in hexafluorobenzene by bromine suggested that other high-temperature substitution reactions might be feasible with similar coreactants. The copyrolysis of chlorine or sulfuryl chloride and hexafluorobenzene at $700{ }^{\circ} \mathrm{C}$ gave good conversions into products. Again, the monosubstituted product, in this case chloropentafluorobenzene, was formed in high yield (80 to $85 \%)$. The conversion of hexafluorobenzene into products (primarily chloropentafluorobenzene) was even higher in this case than in the bromination reaction. However, as in the bromination reaction, chlorination of hexafluorobenzene at high temperatures gave also some polyhalogenated products which have not yet been characterized (except to note that, from its retention time on the vaporphase chromatogram, the major constituent of these products appears to be an isomer of dichlorotetrafluorobenzene).

\section{c. lodine}

The copyrolysis of iodine and hexafluorobenzene gave rather low conversions into products. The low conversion, perhaps, may have resulted from the experimental difficulties encountered in the simultaneous addition of the two reagents. However, the yield of pentafluoroiodobenzene based on unrecovered hexafluorobenzene was excellent $(90 \%)$. No evidence of more highly iodinated products was found, although this may be attributable to the very low conversion into products.

\subsection{Reaction With Water and Ammonia}

Similarly, water and ammonia gave only trace amounts of the corresponding pentafluorophenyl derivatives, pentafluorophenol and pentafluoroaniline, on copyrolysis with hexafluorobenzene. However, it may be possible to increase these low conversions by modifications of certain of the conditions of the copyrolysis reaction.

The results of the above reactions are shown in table 1 .
TABLE 1. Inorganic coreactants

High-temperature reactions of hexafluorobenzene/copyrolysis over glass helices.

\begin{tabular}{|c|c|c|c|c|}
\hline Reactant & Temp & Products & $\begin{array}{r}\text { Conversion } \\
\text { into products }\end{array}$ & $\begin{array}{c}\text { Yield of } \\
\text { major mono } \\
\text { derivative }\end{array}$ \\
\hline $\mathrm{Br}_{2}$ & $\begin{array}{c}{ }^{\circ} \mathrm{C} \\
650 \\
740\end{array}$ & $\begin{array}{l}\mathrm{C}_{6} \mathrm{~F}_{5} \mathrm{Br} \\
\mathrm{C}_{6} \mathrm{~F}_{5} \mathrm{Br} \\
\mathrm{C}_{6} \mathrm{~F}_{4} \mathrm{Br}_{2}(?)\end{array}$ & $\begin{array}{c}\% \\
8 \\
25-30\end{array}$ & $\begin{array}{c}\% \\
94,95 \\
85-90\end{array}$ \\
\hline $\mathrm{Cl}_{2}$ & 700 & $\begin{array}{l}\mathrm{C}_{6} \mathrm{~F}_{5} \mathrm{Cl} \\
\mathrm{C}_{6} \mathrm{~F}_{4} \mathrm{Cl}_{2} \text { (?) etc. }\end{array}$ & 50 & 85 \\
\hline $\mathrm{SO}_{2} \mathrm{Cl}_{2}$ & 700 & $\begin{array}{l}\mathrm{C}_{6} \mathrm{~F}_{5} \mathrm{Cl} \text {, } \\
\mathrm{C}_{6} \mathrm{~F}_{4} \mathrm{Cl}_{2} \text {, etc. }\end{array}$ & 75 & 80 \\
\hline $\mathrm{I}_{2}$ & 650 & $\mathrm{C}_{6} F_{5} \mathrm{I}$ & $<5$ & 90 \\
\hline $\mathrm{H}_{2} \mathrm{O}$ & 700 & $\begin{array}{l}\mathrm{C}_{6} \mathrm{~F}_{5} \mathrm{OH} \\
\mathrm{C}_{6} \mathrm{~F}_{5} \mathrm{H}\end{array}$ & $<5$ & 90 \\
\hline $\mathrm{NH}_{3}$ & 650 & $\mathrm{C}_{6} \mathrm{~F}_{5} \mathrm{NH}_{2}$ & $<5$ & 90 \\
\hline
\end{tabular}

\subsection{Reaction With Fluorohaloalkanes}

Fluorohaloalkanes can undergo an analogous hightemperature reaction with hexafluorobenzene. As before, the pentafluorohalobenzene was the major product. In these reactions, the fluorohaloalkanes serve as the source of reactive halogen species. For example, bromopentafluorobenzene was obtained in excellent yield and fair to good conversions by the copyrolysis of hexafluorobenzene and such bromofluoroalkanes as 1,2-dibromotetrafluoroethane, dibromodifluoromethane, and tribromofluoromethane. The last compound gave the best conversion into bromopentafluorobenzene. In addition to bromopentafluorobenzene, the first two bromofluoroalkanes also gave lesser, though significant, amounts of octafluorotoluene. Trace quantities of what appeared to be dibromo derivatives of hexafluorobenzene were also present in the product mixtures.

Higher conversions of hexafluorobenzene into octafluorotoluene were obtained when trifluoroiodomethane was the coreactant (table 2). In this case, the pentafluorohalobenzene (pentafluoroiodobenzene) was the minor product.

These results are summarized in table 2 .

TABLE 2. Coreactant fluorohaloalkanes

\begin{tabular}{|c|c|c|c|c|}
\hline Reactant & Temp & Products & $\left|\begin{array}{c}\text { Conv. into } \\
\text { products }\end{array}\right|$ & $\begin{array}{c}\text { Yield of } \\
\text { major } \\
\text { mono } \\
\text { derivative }\end{array}$ \\
\hline $\mathrm{CFBr}_{3}$ & $\begin{array}{r}{ }^{\circ} \mathrm{C} \\
680\end{array}$ & $\begin{array}{l}\mathrm{C}_{6} \mathrm{~F}_{5} \mathrm{Br} \text { (major) } \\
\text { (?) } \mathrm{C}_{6} \mathrm{~F}_{4} \mathrm{Br}_{2} \text { (minor) }\end{array}$ & $\begin{array}{l}\% \\
50\end{array}$ & $\begin{array}{l}\% \\
90\end{array}$ \\
\hline $\mathrm{CF}_{2} \mathrm{Br}_{2}$ & 680 & $\begin{array}{l}\mathrm{C}_{6} \mathrm{~F}_{5} \mathrm{rr}^{\text {(major) }} \\
\mathrm{C}_{6} \mathrm{~F}_{5} \mathrm{CF}_{3} \text { (minor) } \\
\text { (?) } \mathrm{C}_{6} \mathrm{~F}_{4} \mathrm{Br}_{2} \text { (trace) }\end{array}$ & 35 & 90 \\
\hline $\mathrm{CF}_{2} \mathrm{BrCF}_{2} \mathrm{Br}$ & 670 & $\begin{array}{l}\mathrm{C}_{6} \mathrm{~F}_{5} 5 \text { (major) } \\
\mathrm{C}_{6} \mathrm{~F}_{5} \mathrm{CF}_{3} \text { (minor) } \\
\text { (?) } \mathrm{C}_{6} \mathrm{~F}_{4} \mathrm{Br}_{2} \text { (trace) }\end{array}$ & 30 & 85 \\
\hline \multirow[t]{2}{*}{$\mathrm{CF}_{3} \mathrm{I}$} & 700 & $\begin{array}{l}\mathrm{C}_{6} \mathrm{~F}_{5} \mathrm{CF}_{3} \text { (major) } \\
\mathrm{C}_{6} \mathrm{~F}_{5} \mathrm{I} \text { (minor) }\end{array}$ & 10 & 90 \\
\hline & 760 & $\begin{array}{l}\text { same products, } \\
\mathrm{C}_{6} \mathrm{~F}_{5} \mathrm{CF}_{3} \text { (major) }\end{array}$ & 20 & 85 \\
\hline
\end{tabular}




\subsection{Reaction With Fluorohaloalkenes}

Early attempts to synthesize octafluorostyrene by copyrolysis of hexafluorobenzene with chlorotrifluoroethylene or bromotrifluoroethylene gave little if any of the desired olefin. However, the corresponding pentafluorohalobenzene was formed in fair conversions and excellent yields. Smaller amounts of higherboiling products were also produced in these pyrolyses, but have not been further characterized.

The results are shown in table 3 .

TABLE 3. Coreactant fluoroolefins

\begin{tabular}{|c|c|c|c|c|}
\hline Reactant & Temp & Products & $\begin{array}{c}\text { Conversion } \\
\text { into products }\end{array}$ & $\begin{array}{c}\text { Yield of } \\
\text { major mono } \\
\text { derivative }\end{array}$ \\
\hline $\begin{array}{l}\mathrm{CF}_{2}=\mathrm{CFCl} \\
\mathrm{CF}_{2}=\mathrm{CFBr} \\
\mathrm{CF}_{2}=\mathrm{CF}_{2} \\
\mathrm{CF}_{3} \mathrm{CF}=\mathrm{CF}_{2}\end{array}$ & $\begin{array}{l}{ }^{\circ} \mathrm{C} \\
670 \\
690 \\
850 \\
800\end{array}$ & $\begin{array}{l}\mathrm{C}_{6} \mathrm{~F}_{5} \mathrm{Cl} \text {, etc. } \\
\mathrm{C}_{6} \mathrm{~F}_{5} \mathrm{Br} \text {, etc. } \\
\mathrm{C}_{6} \mathrm{~F}_{5} \mathrm{CF}_{3} \\
\mathrm{C}_{6} \mathrm{~F}_{5} \mathrm{CF}_{3}\end{array}$ & $\begin{array}{ll}\% & \\
& 30 \\
& 20 \\
& 20 \\
& 15\end{array}$ & $\begin{array}{l}\% \\
80-85 \\
80-85 \\
90-95 \\
90-95\end{array}$ \\
\hline
\end{tabular}

\subsection{Reaction With Perfluoroalkenes}

The copyrolysis of hexafluorobenzene with perfluoroolefins, such as tetrafluoroethylene and hexafluoropropylene, resulted in excellent yields of octafluorotoluene. The conversion into products was of the order of 15 to 20 percent at temperatures of 800 to $850{ }^{\circ} \mathrm{C}$ (table 3 ).

\subsection{Reaction With Inorganic Salts}

A related study was made of the behavior of hexafluorobenzene at high temperatures with certain inorganic salts. The technique employed in these reactions usually involved the passage of hexafluorobenzene under a stream of nitrogen through a fused silica tube filled throughout the heated zone with carbon pellets which had been impregnated with the appropriate inorganic salt. The results are shown in table 4 .

TABLE 4. Pyrolysis of $\mathrm{C}_{6} \mathrm{~F}_{6}$ in contact with inorganic salt sorbed by carbon pellets

\begin{tabular}{|c|c|c|c|}
\hline $\begin{array}{c}\text { Tube } \\
\text { packing }\end{array}$ & Temp & $\begin{array}{l}\text { Products and } \\
\text { approximate } \\
\text { yield }\end{array}$ & Conversion \\
\hline & ${ }^{\circ} \mathrm{C}$ & & $\%$ \\
\hline $\mathrm{KOH} /$ carbon & 500 & $\mathrm{C}_{6} \mathrm{~F}_{5} \mathrm{OH}(40 \%), \mathrm{C}_{6} \mathrm{~F}_{5} \mathrm{H}(40 \%)$ & 10 \\
\hline LiI/carbon & 570 & $\mathrm{C}_{6} \mathrm{~F}_{5} \mathrm{I}(20 \%), \mathrm{C}_{6} \mathrm{~F}_{5} \mathrm{H}(40 \%)$ & 30 \\
\hline $\mathrm{KI} /$ carbon & 500 & $\mathrm{C}_{6} \mathrm{~F}_{5} \mathrm{I}(40 \%), \mathrm{C}_{6} \mathrm{~F}_{5} \mathrm{H}(40 \%)$ & 15 \\
\hline $\mathrm{KBr} /$ carbon & 600 & $\mathrm{C}_{6} \mathrm{~F}_{5} \mathrm{Br}(60 \%), \mathrm{C}_{6} \mathrm{~F}_{5} \mathrm{H}(30 \%)$ & 20 \\
\hline $\mathrm{KCN} /$ carbon & 570 & $\mathrm{C}_{6} \mathrm{~F}_{5} \mathrm{CN}(70 \%), \mathrm{C}_{6} \mathrm{~F}_{5} \mathrm{H}(20 \%)$ & 5 \\
\hline $\mathrm{CaCl}_{2}(4 \text { mesh })^{\mathrm{a}}$ & 700 & $\mathrm{C}_{6} \mathrm{~F}_{5} \mathrm{Cl}(90 \%)$ & 10 \\
\hline
\end{tabular}

${ }^{a}$ Without carbon pellets.

The substitution of chlorine, bromine, or iodine in aromatic compounds by fluorine by means of alkali fluorides, such as potassium fluoride, is a well-known process [18-22]. The reverse process, the replacement of a nuclear fluorine atom by a less electronegative halogen atom by means of its alkali or alkaline earth salt, has not yet been reported. However, as shown in table 4 , it is indeed possible to replace at least one of the fluorines of hexafluorobenzene by a less electronegative halogen by reaction of this organic compound with an alkali or alkaline earth salt at elevated temperatures. For example, hexafluorobenzene and lithium iodide impregnated on carbon pellets gave, at $570{ }^{\circ} \mathrm{C}$, a 20 percent yield of pentafluoroiodobenzene along with a 40 percent yield of pentafluorobenzene. The conversion into products was 30 percent. A fair quantity of free iodine was also produced, but only a small quantity of higher-boiling (above $162{ }^{\circ} \mathrm{C}$ ) products. The other salts impregnated on carbon pellets gave similar results with hexafluorobenzene. The principal products were the expected monosubstituted derivatives and pentafluorobenzene. The origin of the pentafluorobenzene is at present unknown. Conceivably, it may arise from the decomposition of the initially formed, monosubstituted derivative in the presence of some hydrogen source. Direct hydrogenolysis of the hexafluorobenzene is also possible. The formation of pentafluorobenzene apparently requires the use of carbon pellets. The impregnated pellets were usually formed by evaporation of an aqueous solution of the salt in the presence of the carbon pellets. The impregnated pellets were dried in the reactor at about $500{ }^{\circ} \mathrm{C}$ until no more water could be detected in the trapping system. The reactor was then heated to the appropriate reaction-temperature and the traps were checked again for the presence of any moisture. Unless some water remained tightly occluded to the impregnated pellets, it would not seem to be the source of hydrogen for the hydrogenation reaction. Nonvolatile, hydrogencontaining impurities in the carbon pellets are another possible source of hydrogen.

In one experiment, the carbon pellets were omitted and only the inorganic salt, calcium chloride $\left(\mathrm{CaCl}_{2}\right)$, was employed as the packing material. The passage of hexafluorobenzene over anhydrous calcium chloride (4 mesh) heated to $700^{\circ} \mathrm{C}$ gave a 10 percent conversion into products. The major product $(90 \%)$ was the expected chloropentafluorobenzene. A small amount of higher-boiling material (polychloro derivatives of hexafluorobenzene) was also present. However, no trace of pentafluorobenzene was observed in the products of this pyrolysis. The results of these experiments are summarized in table 4.

\section{Discussion}

As previously indicated, earlier work seemed to suggest that the displacement of nuclear fluorine in polyfluoro aromatics could be achieved only by reaction with certain basic nucleophiles. However, recent work in these and other laboratories [4-6] has shown that homolytic substitution reactions are indeed possible with hexafluorobenzene. The results of the present study clearly demonstrate that the replacement 
of nuclear fluorine can also be accomplished by the reaction of hexafluorobenzene with nonnucleophilic or weakly nucleophilic reagents at elevated temperatures.

The excellent thermal stability of hexafluorobenzene $[1,2,23-25]$ lends itself quite well to high-temperature reactions where extensive decomposition and carbonization are common problems in the pyrolytic reactions of many organic compounds.

Other polyfluoro aromatic compounds can also be used in these high-temperature substitution reactions. However, some modifications of the reaction conditions may be necessary, depending on the nature of the polyfluoro aromatic compound employed. For example, a recent experiment involving the hightemperature bromination of pentafluorobenzene demonstrated that it is possible, by lowering the reaction temperature, to replace selectively the nuclear hydrogen rather than a nuclear fluorine. Thus, at 500 to $550{ }^{\circ} \mathrm{C}$, the nuclear hydrogen only was displaced by bromine, whereas, at 650 to $700{ }^{\circ} \mathrm{C}$, the bromination was less selective and fluorine was displaced as well.

Another important factor to be considered is the thermal stability of the polyfluoro aromatic compound. If it is thermally less stable than hexafluorobenzene, this fact must be considered in the copyrolysis reaction. In this connection, it would seem important to consider also the relative thermal stability of the expected product or products of the pyrolytic reaction. If the product breaks down at the temperature of reaction, it may be necessary to work at either lower temperatures or at shorter contact times, or both. In summary, it would appear that the several variables involved in these high-temperature reactions of polyfluoro aromatic compounds, such as the types of reactor tube, its dimensions, the packing material, the relative concentration of the reactants, the contact time, etc., should all be evaluated in order to optimize the yield of the desired product.

\section{Mechanism of the High-Temperature Substitution Reactions}

\subsection{Free-Radical Substitution Mechanisms}

The copyrolysis experiments on hexafluorobenzene with such reactants as bromine, chlorine, dibromodifluoromethane, or trifluoroiodomethane probably proceed by a free-radical mechanism. Several mechanisms for the halogenation type of reaction can be postulated.

One possible mechanism is similar to that postulated for the high-temperature vapor-phase halogenation of benzene [26-28]. This mechanism is analogous to that of most free-radical, aliphatic, substitution reactions and involves such chain-propagating steps as the following:

$$
\begin{aligned}
& \text { (1) } X \cdot+\mathrm{C}_{6} \mathrm{H}_{6} \longrightarrow \mathrm{C}_{6} \mathrm{H}_{5} \cdot+\mathrm{H} X \\
& \text { (2) } \mathrm{C}_{6} \mathrm{H}_{5} \cdot+X_{2} \longrightarrow \mathrm{C}_{6} \mathrm{H}_{5} X+X \text {. }
\end{aligned}
$$

$X=\mathrm{Br}, \mathrm{Cl}$, etc.

Applied to the high-temperature reactions of hexafluorobenzene, this mechanism becomes:

$$
\begin{aligned}
& \text { (1) } X \cdot+\mathrm{C}_{6} \mathrm{~F}_{6} \longrightarrow \mathrm{C}_{6} \mathrm{~F}_{5} \cdot+X \mathrm{~F} \\
& \text { (2) } \mathrm{C}_{6} \mathrm{~F}_{5} \cdot+X_{2} \longrightarrow \mathrm{C}_{6} \mathrm{~F}_{5} X+X \text {. }
\end{aligned}
$$

$X=\mathrm{H}, \mathrm{Cl}, \mathrm{Br}, \mathrm{I}$, or $\mathrm{CF}_{3}$.

Another possible mechanism involves the addition of the radical species, $X \cdot$, to hexafluorobenzene to give the intermediate cyclohexadienyl radical (I), which then can give the monosubstitution product by displacement of fluorine (probably as $X \mathrm{~F}$ ). This mechanism can be represented as shown below:

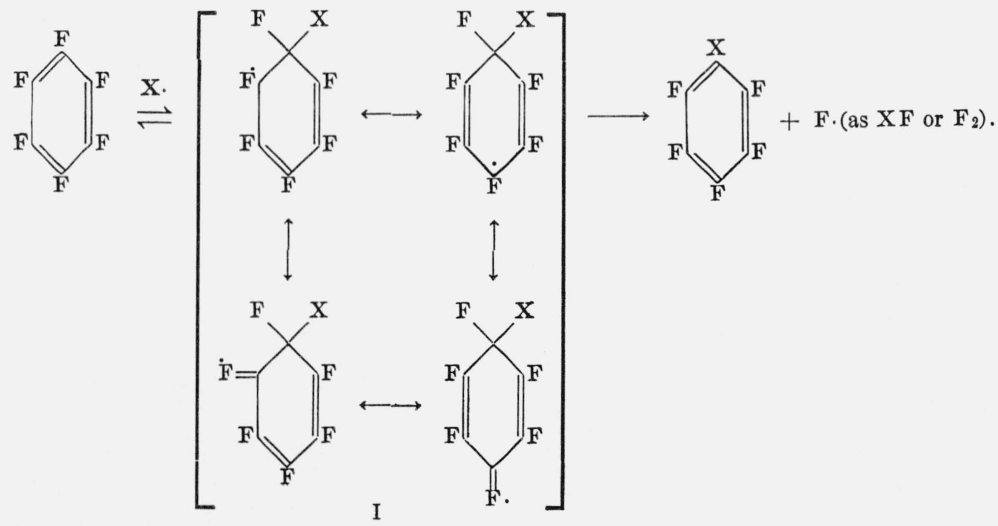


A third possible mechanism, somewhat similar to the preceding one, is represented by the sequence of reactions shown below:

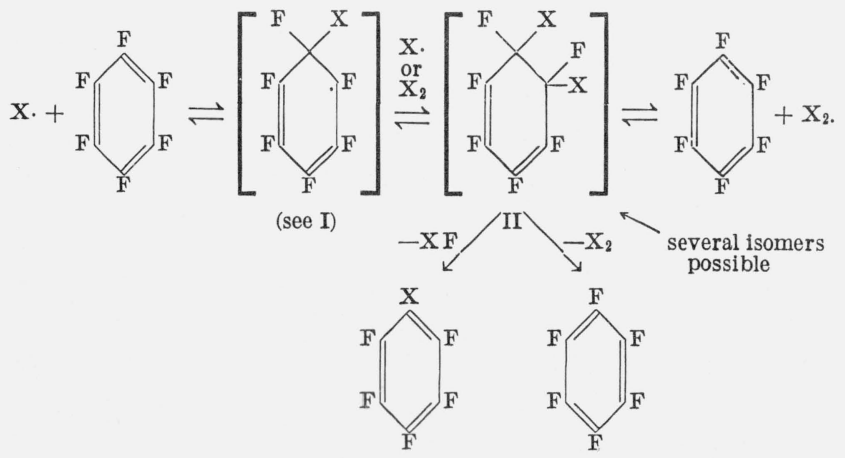

Unlike the preceding mechanism, the intermediate (II) in this case is not a cyclohexadienyl radical, but an unstable cyclohexadiene which can undergo elimination of $X \mathrm{~F}$. The intermediate cyclohexadiene can be formed either in two steps from hexafluorobenzene by successive addition of the radical species $X$ or in one step by a simultaneous addition of the elements of $X_{2}$ across vinylic positions of the aromatic ring. Aromatization of the unstable cyclohexadiene intermediate can then proceed by loss of either $X \mathrm{~F}$ or $X_{2}$ to give the desired monosubstituted pentafluorobenzene or the starting material, hexafluorobenzene. Presumably, the loss of $X \mathrm{~F}$ can take place, as well as the energetically more favored loss of $X_{2}$, if it is assumed that a cis-elimination process is necessary, or at least favored, in dehalogenation. Then, the trans isomer of the cyclohexadiene intermediate (II) should lead to the formation of the monosubstituted pentafluorobenzene by loss of $X \mathrm{~F}$. Conversely, the cis isomer of the cyclohexadiene intermediate (II) should revert to hexafluorobenzene by loss of $X_{2}$. The formation of disubstituted derivatives can occur either by a similar, secondary reaction involving the primary product, or, perhaps, from hexafluorobenzene by the transient formation of the correct stereoisomer of a cyclohexene derivative. As an extension of this mechanism, it could also be argued that, in the hightemperature halogenation reactions, the transient intermediates may be certain stereoisomers of the hexafluorohexahalocyclohexane that could, by cis elimination, lead to the observed products.

\subsection{Difluoromethylene Mechanism for the Formation of Octafluorotolvene}

In the copyrolysis of hexafluorobenzene with such coreactants as dibromodifluoromethane, tetrafluoroethylene, and hexafluoropropylene, octafluorotoluene is one of the principal products. The formation of this compound can be explained by a "net insertion" mechanism [29] involving the reactive species, difluoromethylene. Several mechanistic paths are possible for this type of reaction, as shown below:

Disproportionation-Combination

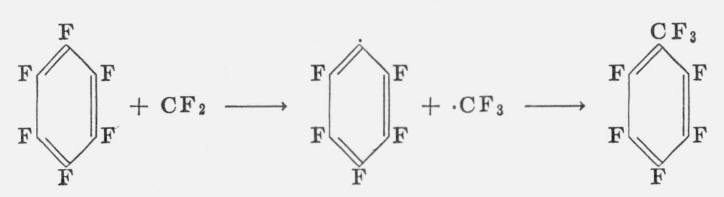

Addition-Rearrangement

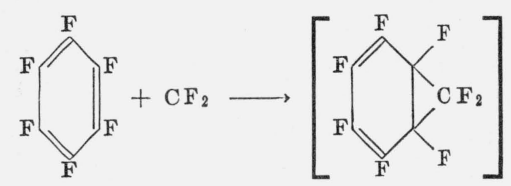

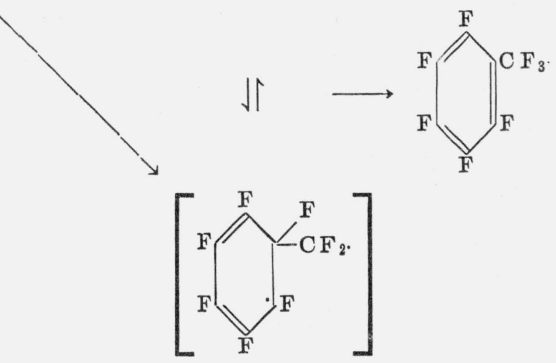

Net insertion reactions of difluoromethylene have previously been reported involving insertion into $\mathrm{P}-\mathrm{F}$, $\mathrm{N}-\mathrm{F}$, and $\mathrm{C}-\mathrm{F}$ bonds [29-31]. The few reported insertion reactions of difluoromethylene into $\mathrm{CF}$ bonds all seem to involve a vinylic $\mathrm{C}-\mathrm{F}$ bond [30], such as is demonstrated by the following reaction:

$$
\mathrm{CF}_{2}+\mathrm{CF}_{2}=\mathrm{CF}_{2} \rightarrow \mathrm{CF}_{3} \mathrm{CF}=\mathrm{CF}_{2}
$$

Insertion reactions at other than vinylic sites have thus far not been observed for difluoromethylene and fluorocarbons. The exclusive reaction of difluoromethylene with a vinylic $\mathrm{C}-\mathrm{F}$ bond seems to be borne out by the following reaction, in which only perfluoroisobutylene is formed [30],

$$
\mathrm{CF}_{2}+\mathrm{CF}_{3} \mathrm{CF}=\mathrm{CF}_{2} \rightarrow\left(\mathrm{CF}_{3}\right)_{2} \mathrm{C}=\mathrm{CF}_{2} .
$$

It is not unexpected, therefore, that hexafluorobenzene would undergo an analogous reaction with difluoromethylene.

\subsection{Mechanism of High-Temperature Reaction of Hexafluorobenzene With Inorganic Salts}

The reaction of hexafluorobenzene with certain inorganic, ionic compounds, sorbed by carbon pellets, may follow the usual ionic mechanism for nucleophilic attack on hexafluorobenzene [15]. On the other hand, the mechanism may be more complex, and may actually involve some free-radical process as well. The 
same may be said for the reaction of hexafluorobenzene with calcium chloride. Whether the elevated temperature of these reactions permit what are normally weak nucleophiles to react with hexafluorobenzene by a nucleophilic path, or whether a more complicated mechanism is, indeed, involved, remains to be determined. Continued study along these lines is planned in order to elucidate further the nature of these reactions.

\section{Conclusion}

Because of their high thermal stability, perfluoro aromatic compounds, such as hexafluorobenzene, can undergo many reactions at high temperatures without danger of excessive substitution or destruction of the aromatic nucleus. In this respect, they offer definite advantages over analogous aromatic hydrocarbons in the field of high-temperature chemistry. Furthermore, it appears that perfluoro aromatic compounds differ significantly from perfluoro aliphatic conpounds in their chemical behavior at high temperatures. For example, the reaction of perfluoroalkanes with such reactants as bromine and chlorine results in cleavage of the carbon-carbon bond rather than the carbonfluorine bond of the fluorocarbon [32]. With hexaflurorbenzene, however, cleavage of the carbonfluorine bond predominates over cleavage of the carbon-carbon bond.

Of special theoretical interest are the results obtained from the high-temperature reactions of bromine and tribromofluoromethane, respectively, with hexafluorobenzene. From these results, a plausible case can be made for the formation of bromopentafluorobenzene in the pyrolysis of tribromofluoromethane by a secondary reaction of the initially formed hexafluorobenzene with bromine radicals or some type of brominecontaining species.

In addition to their theoretical interest, these hightemperature reactions are of great potential value in that they provide a direct method for the synthesis of pentafluorohalobenzenes and other similar derivatives from hexafluorobenzene in one step, a process not previously known.

\section{Experimental Procedure}

\subsection{Apparatus and Method}

The reactor used in this study was a fused silica tube, $54 \mathrm{~cm}$ by $2 \mathrm{~cm}$ (ID), equipped with a 24/40 standard-taper joint at each end. The tube was placed in the vertical position in an electric furnace, and the lower end was connected to three traps in series cooled by a solid carbon dioxide-acetone slurry. The last trap carried a drying tube filled with anhydrous calcium sulfate. The upper end of the tube was equipped with one or two pressure-equalizing dropping funnels carrying a gas inlet-tube. The pyrolysis temperature was ascertained by an ironconstantan thermocouple fastened at one end to the outside of the reactor tube, midway in the heated zone (about $25 \mathrm{~cm}$ ), and connected at the other end to a pyrometer. In the copyrolysis experiments, the fused silica tube was packed throughout the heated zone with borosilicate glass helices ( $1 / 8 \mathrm{in})$. In the hightemperature reactions with inorganic salts, the reactor tube was packed throughout the heated zone with activated carbon pellets (4 to 6 mesh), which had been impregnated with the appropriate inorganic salt. The ratio of inorganic salt to carbon pellets was usually 1 to 1 by weight. The impregnated pellets were dried prior to use by gradually preheating the reactor for about $24 \mathrm{hr}$ until the desired reaction-temperature was attained. All the pyrolytic reactions of hexafluorobenzene were performed under a slow stream of nitrogen gas at approximately atmospheric pressure.

In the copyrolysis experiments, the following techniques were employed:

(1) For reactants miscible with hexafluorobenzene, a solution of known concentration was added at a low drop-rate (approximately 1 per $10 \mathrm{sec)}$ to the reactor by means of a pressure-equalizing dropping funnel.

(2) Gaseous reactants, such as chlorine, were allowed to distil slowly into the reactor through a gas inlet-tube, the end of which was immersed in the hexafluorobenzene contained in the dropping funnel. The hexafluorobenzene was added dropwise, or by codistillation with the gaseous reactant.

(3) For reactants that were not completely miscible with hexafluorobenzene (e.g., bromine), it was necessary to employ two pressure-equalizing dropping funnels, connected in parallel and attached to the reactor by means of a $\mathrm{Y}$-adapter. The drop-rate for each reactant was adjusted accordingly, so that the two reactants were always present in the reactor in low concentration.

In the experiments involving inorganic salts as the coreactant, the hexafluorobenzene was simply added at a certain drop-rate (approximately 1 drop per 15 or $20 \mathrm{sec}$ ) to the reactor via the dropping funnel. An alternative technique was to distil the hexafluorobenzene slowly through the reactor, either at atmospheric or reduced pressure.

The pyrolyzates from the various runs were processed by the usual techniques, such as washing to remove corrosive materials, drying, and distillation. When separation of product by distillation was difficult or impractical, preparative vapor-phase chromatography was employed.

Since the major products from these reactions were known compounds, preliminary identification was made by comparison of physical properties. When the compound was available, comparison of vaporphase chromatographic retention-times was used to establish identity. Mass-spectroscopic analysis was used to confirm the preliminary identification. Yields were usually calculated by vapor-phase chromatographic analysis of the washed and dried pyrolyzate.

\subsection{Copyrolysis of Hexafluorobenzene and Bromine}

Approximately $14.4 \mathrm{~g}(0.09 \mathrm{~mole})$ of bromine and $5.5 \mathrm{~g}(0.03 \mathrm{~mole})$ of hexafluorobenzene were copyrolvzed at $650{ }^{\circ} \mathrm{C}$. The pyrolyzate, after removal of 
unreacted bromine, weighed 5.7 g. Examination of the pyrolyzate revealed that two components were present. About 90 percent of the mixture was hexafluorobenzene; the other component accounted for the remaining 10 percent. The second component was shown to be bromopentafluorobenzene by comparison of retention times with that of an authentic sample. Isolation of the components, by preparative vaporphase chromatography, using an 8 - $\mathrm{ft}$ by $3 / 4$-in column packed with 40/60 mesh acid-washed chromosorb $\mathrm{W}$, which was coated with 25 percent by weight of silicone elastomer, gave $5.1 \mathrm{~g}$ of recovered hexafluorobenzene and $0.5 \mathrm{~g}$ of bromopentafluorobenzene. The identification of the second component was confirmed by mass-spectroscopic analysis (parent mass peak at 247) and by comparison of boiling points (bp $136{ }^{\circ} \mathrm{C}$ ). The conversion into the bromo derivative was 8 percent and the yield was 94 percent.

The same experiment was repeated, but at $740{ }^{\circ} \mathrm{C}$. Vapor-phase chromatographic analysis revealed that the conversion of hexafluorobenzene into bromopentafluorobenzene was increased about three-fold. Two other products (higher boiling) were also formed, in addition to the monobromobenzene, but they were present to the extent of only 5 to 10 percent. The conversion into products was about 25 to 30 percent, and the yield of bromopentafluorobenzene was 85 to 90 percent. The higher-boiling products have not yet been characterized.

\subsection{Reaction of Hexafluorobenzene With Lithium lodide}

Approximately $11.0 \mathrm{~g}(0.44$ mole $)$ of hexafluorobenzene was dropped (4 drops/min) through the reactor, packed with carbon pellets which had been impregnated with lithium iodide ( 1 to 1 weight ratio). The reactor tube was kept at $570{ }^{\circ} \mathrm{C}$, and the reaction was performed under a slow stream of nitrogen at atmospheric pressure. A fair quantity of free iodine formed on adding the hexafluorobenzene. The pyrolyzate, after removal of the iodine by washing with a saturated solution of sodium thiosulfate and drying, weighed $8.6 \mathrm{~g}$. Vapor-phase chromatographic analysis revealed the presence of three components. The first component $(90 \%)$ was hexafluorobenzene. After isolation the second component was shown by massspectroscopic analysis to be pentafluorobenzene. Similarly, the third component was identified as pentafluoroiodobenzene. A very small amount of a higherboiling component was also isolated, but this has not yet been characterized. The conversion into products, based on unrecovered hexafluorobenzene, was 30 percent (7.8 $\mathrm{g}$ of hexafluorobenzene was recovered). The yield of the iodo derivative was about 20 percent, and that of pentafluorobenzene was about 40 percent.

\section{References}

[1] Y. Desirant, Bull. Acad, Roy, Belg. Classe Sci. 41, [5], 759 (1955).

[2] Y. Desirant, Bull. Soc. Chim. Belg. 67, 676 (1958).

[3] J. A. Godsell, M. Stacey, and J. C. Tatlow, Nature 178, 199 (1956).

[4] R. E. Florin, W. J. Pummer, and L. A. Wall. J. Res. NBS 62, 119 (1959) RP 2940.

[5] J. M. Antonucci and L. A. Wall, Abstracts Papers 145th Am. Chem. Soc. Meeting, 18M (1963).

[6] P. A. Claret, J. Coulson, and G. H. Williams, Chem. Ind. (London) 228 (1965).

[7] W. J. Pummer and L. A. Wall, Science 12 7, 643 (1958).

[8] E. J. Forbes, R. D. Richardson, and J. C. Tatlow, Chem. Ind. (London) 630 (1958).

[9] J. M. Birchall and R. N. Haszeldine, J. Chem. Soc. 13 (1959).

[10] E. J. Forbes, R. D. Richardson, M. Stacey, and J. C. Tatlow, ibid. 2019 (1959).

[11] G. M. Brooke, J. Burdon, M. Stacey, and J. C. Tatlow ibid. 1768 (1960).

[12] F. Robson, M. Stacey, R. Stephens, and J. C. Tatlow, ibid. 4754 (1960).

[13] A. K. Barbour, M. W. Buxton, P. L. Coe, R. Stephens, and J. C. Tatlow, ibid. 808.(1961).

[14] J. M. Birchall and R. N. Haszeldine, ibid. 3719 (1961).

[15] L. A. Wall, W. J. Pummer, J. E. Fearn, and J. M. Antonucci, J. Res. NBS 67A (Phys. and Chem.) No. 5, 481 (1963).

[16] M. Hellman, E. Peters, W. J. Pummer, and L. A. Wall, J. Am. Chem. Soc. 79, 5654 (1957).

[17] J. E. Fearn, R. E. Lowry, W. J. Pummer, and L. A. Wall, J. Res. NBS 65A (Phys. and Chem.) No. 3, 167 (1959).

[18] G. C. Finger and C. W. Kruse, J. Am. Chem. Soc. 78, 6034 (1956).

[19] G. C. Finger and L. D. Starr, ibid. 81, 2674 (1959).

[20] N. N. Vorozhtsov, Jr., and G. G. Yakobson, Nauch. Dokl. Vyshei Shkoly Khim. i. Khim Technol. [1] 122 (1958).

[21] G. C. Finger, L. D. Starr, D. R. Dickerson, H. S. Gutowsky, and J. Hamer, J. Org. Chem. 28, 1666 (1963).

[22] J. T. Maynard, ibid. 28, 112 (1963).

[23] V. H. Dibeler, R. M. Reese, and F. L. Mohler, J. Chem. Phys. 26, 304 (1957).

[24] R. E. Donadio, W. J. Pummer, and L. A. Wall, J. Am. Chem. Soc. 82, 4846 (1960).

[25] P. L. Coe, C. R. Patrick, and J. C. Tatlow, Tetrahedron 9, 240 (1960).

[26] O. C. Derner and M. T. Edmison, Chem. Rev. 57, 77 (1957).

[27] G. H. Williams, Homolytic Aromatic Substitution (Pergamon Press, N.Y., 1960).

[28] E. S. Huyser and E. Bedard, J. Org. Chem. 29, 1588 (1964).

[29] S. Andreades, Chem. Ind. (London) 782 (1962).

[30] B. Atkinson and V. A. Atkinson, J. Chem. Soc. 2086 (1957).

[31] W. Mohler, Preprints of the Second Intern. Symp. Fluorine Chem., Estes Park, Colorado, July 1962, p. 411.

[32] J. Brice, W. H. Pearlson, and J. H. Simons, J. Am. Chem. Soc. 71, 2499 (1949).

(Paper 70A6-420) 